\title{
Pharmacokinetics in Rat Plasma and Tissue Distribution in Mice of Galangin Determined by UHPLC-MS/MS
}

\author{
Weijian Ye ${ }^{1}$, Wei Sun ${ }^{1}$, Ruijie Chen ${ }^{1}$, Zhe Wang ${ }^{1}$, Xiao Cui ${ }^{1}$, Hui Zhang ${ }^{1}$, Shuyi Qian ${ }^{2}$, Qi Zheng ${ }^{2}$, \\ Yangfeng $\mathrm{Zhou}^{2}$, Jiafeng $\mathrm{Wan}^{2}$, Jiali $\mathrm{Xu}^{2}$, Xianqin Wang ${ }^{2 *}$ and Yunfang $\mathrm{Zhou}^{3 *}$ \\ ${ }^{1}$ The Second Affiliated Hospital and Yuying Children's Hospital of Wenzhou Medical University, Wenzhou 325027, China \\ ${ }^{2}$ Analytical and Testing Center, Wenzhou Medical University, Wenzhou 325035, China \\ ${ }^{3}$ Laboratory of Clinical Pharmacy, The People's Hospital of Lishui, Lishui, 323000, China
}

Received: 26 September 2017; accepted: 22 October 2017

\begin{abstract}
Galangin (GAL), the major bioactive flavonol extracted from Alpinia officinarum Hance (Zingiberaceae), has attracted much attention due to its multiple biological activities. To develop a fast, reliable, and sensitive ultrahighperformance liquid chromatography-tandem mass spectrometry (UHPLC-MS/MS) method for the quantification of GAL in rat plasma and mouse tissues. UHPLC-MS/MS using electrospray ionization operating in negative-ion mode was used to determinate GAL in 18 rats receiving three doses of GAL ( 2 and $9 \mathrm{mg} / \mathrm{kg}$ by intravenous injection, $5 \mathrm{mg} / \mathrm{kg}$ by oral administration), with six rats for each dose. Blood samples were collected at $0.0333,0.25$, $0.5,1,2,4,6$ and $8 \mathrm{~h}$. A total of 25 mice received $18 \mathrm{mg} / \mathrm{kg}$ GAL by intraperitoneal injection. Liver, heart, lung, spleen, brain, and kidney tissue samples were collected at $0.25,0.5,2,4$, and $6 \mathrm{~h}$. The precision of the method was better than $12.1 \%$, while the accuracy ranged from $-4.8 \%$ to $8.1 \%$. The results of pharmacokinetics demonstrated rapid GAL absorption $\left(t_{\max }\right.$ of $\left.0.25 \mathrm{~h}\right)$, fast elimination $\left(t_{1 / 2}<1.1 \mathrm{~h}\right)$ after three different dosages, and an absolute bioavailability of $\sim 7.6 \%$. Tissue distribution analysis revealed abundant GAL in liver, kidney, spleen, and lung and smaller amounts in brain. The developed method proved fast $(3 \mathrm{~min})$, efficient, and reliable, with high selectivity for the quantitative analysis of GAL in biological samples. This is the first study to identify the target tissues of GAL, and the results may help to elucidate the mechanisms underlying its therapeutic effects in vivo.
\end{abstract}

Keywords: Alpinia officinarum Hance (Zingiberaceae), UHPLC-MS/MS, quantification

\section{Introduction}

Galangin (3,5,7-trihydroxyflavone, GAL) is a natural flavonol and bioactive component extracted from Alpinia officinarum Hance (Zingiberaceae) that has long been used as a herbal medicine and spice in South Africa and Asia. GAL exhibits neurovascular protective properties and acts through $\mathrm{Wnt} / \beta$-catenin coupled with the HIF-1 $\beta$ /VEGF pathway, which might make it a potent candidate as an anti-ischemic stroke drug [1]. In addition, GAL has anti-tumor [2-4], anti-oxidative [5, 6], anti-inflammatory $[7,8]$, and anti-microbial [9-11] activities. These diverse therapeutic activities are accompanied by low cytotoxicity [2] and genotoxicity [5]; hence, GAL has attracted much attention, but further investigation is necessary if its potential as a medicinal agent is to be realized.

Currently, available procedures suitable for analysis of GAL include high-performance liquid chromatography (HPLC) [12], ultra-performance liquid chromatography (UPLC) [13], liquid chromatography-mass spectrometry (LC-MS) [14], and LC-MS/MS [15-17]. Feng et al. developed a UPLC approach for determination of GAL in rat plasma with a lower limit of quantification (LLOQ) of $10 \mathrm{ng} / \mathrm{mL}$ using liquid-liquid extraction for sample preparation, and the method was applied to study pharmacokinetics after oral (p.o.) administration [13]. Careri et al. established an LC-MS method for the analysis of several flavonoids including GAL [14]. Chen et al. developed an LC-MS/MS approach with an LLOQ of $2 \mathrm{ng} / \mathrm{mL}$ for quantifying GAL in rat plasma [15]. Gardana et al. developed an LC-MS/MS method for determination of different polyphenols (including GAL) with an LLOQ of $10 \mathrm{ng} / \mathrm{mL}$ in human plasma to assess propolis intake [17]. Ristivojevic et al. developed a UHPLC-linear trap

* Authors for correspondence: lankywang@163.com, zyf2808@126.com quadrupole (LTQ)/MS/MS method for analysis of the phenolic profile of raw materials from Serbian poplar-type propolis. However, the tissue distribution of GAL has not been reported [16]. Tissue distribution studies coupled with pharmacokinetics play a vital role in understanding drug features and facilitate the determination of systemic concentrations that inform on efficiency and toxicity.

Since biomatrices usually occur as complex mixtures, a long analysis time is usually needed for HPLC analysis to achieve complete separation, making the abovementioned LC-MS and LC-MS/MS methods time-consuming (more than 4 min per run). The recently developed UHPLC method can increase the speed of chromatographic separations, with good resolution and sensitivity. A triplequadrupole mass spectrometer is widely used in quantification due to its high sensitivity and selectivity. Therefore, UHPLC-MS/MS is becoming a useful technique for pharmacokinetics, tissue distribution analysis, and drug metabolite identification in biological samples due to the increased speed of analysis, higher separation efficiency and resolution, lower time consumption, and improved sensitivity and accuracy [18]. Both pharmacokinetic evaluation and tissue distribution analysis require a highly efficient and reliable analytical method, and UHPLC-MS/MS can satisfy this requirement. In the present study, a fast, reliable, and sensitive method for the quantification of GAL was developed and validated using fisetin as an internal standard (IS) and applied to pharmacokinetic analysis in rats and exploration of tissue distribution in mice.

\section{Materials and Methods}

Chemicals and Materials. GAL (purity $>98 \%$ ) and fisetin (IS, purity $>98 \%$ ) were purchased from Chengdu Must BioTechnology Co. Ltd. (Chengdu, China). HPLC-grade formic

This is an open-access article distributed under the terms of the Creative Commons Attribution-NonCommercial 4.0 International License (https://creativecommons.org/licenses/by-nc/4.0/), which permits unrestricted use, distribution, and reproduction in any medium for non-commercial purposes, provided the original author and source are credited, a link to the CC License is provided, and changes - if any - are indicated. 
acid, methanol, and acetonitrile were obtained from Merck (Darmstadt, Germany). Water was purified by a Milli-Q system from Millipore (Molsheim, France).

Analytical Instruments. UHPLC-MS/MS was performed using an Agilent 1290 UHPLC system and a 6420 series TripleQuadrupole Tandem Mass Spectrometer (Agilent, Santa Clara, CA, USA) equipped with an electrospray ionization (ESI) source. Mass Hunter software (version B.07.00, Agilent) was used for data acquisition, system control, and statistical calculation.

Animals. Eighteen Sprague-Dawley (SD) rats (180-220 g, 8 weeks old) were used for the pharmacokinetic study, and 25 ICR mice ( 8 weeks old) were used for the tissue distribution analysis. Animals were obtained from and housed at the Laboratory Animal Research Center of Wenzhou Medical University (Wenzhou, China). All research protocols and the use of animals were approved by the Animal Care and Use Committee of Wenzhou Medical University. Apart from a $12 \mathrm{~h}$ prohibition of feeding prior to dosing, food and water were freely available.

UHPLC-MS/MS Conditions. Separation was achieved by injecting a $4 \mu \mathrm{L}$ sample onto an Agilent ZORBAX Eclipse Plus C18 Rapid Resolution HD column $(2.1 \times 50 \mathrm{~mm}, 1.8 \mu \mathrm{m})$ maintained at $30{ }^{\circ} \mathrm{C}$, with an Agilent ZORBAX Eclipse Plus $\mathrm{C} 18(2.1 \times 5 \mathrm{~mm}, 1.8 \mu \mathrm{m})$ used as a guard column. The mobile phase consisted of solvent A $(0.1 \%$ formic acid-water, $\mathrm{v} / \mathrm{v})$ and solvent B (acetonitrile). The gradient elution program was as follows: $0-0.1 \mathrm{~min}, 15 \% \mathrm{~B}$; $0.1-0.2 \mathrm{~min}, 15 \%$ to $100 \% \mathrm{~B}$; and $0.2-2.3 \mathrm{~min}, 100 \% \mathrm{~B}$. The column was equilibrated in $0.7 \mathrm{~min}$, the total run time was $3 \mathrm{~min}$, and the flow rate was $0.4 \mathrm{~mL} / \mathrm{min}$.

The MS/MS system was operated in ESI negative-ion multiple reaction monitoring (MRM) mode with two transitions $\mathrm{m} / \mathrm{z}$ of $269.1 \rightarrow 169.1$ (quantitative ion), 222.8, and a fragmentor voltage $(F)$ of $152 \mathrm{~V}$ for GAL, and $\mathrm{m} / \mathrm{z} 285.1 \rightarrow 135.0$ (quantitative ion), 121.0, and $F$ of $160 \mathrm{~V}$ for IS (Figure 1). The collision energy (CE) was set to 27 and $21 \mathrm{eV}$ for GAL and IS, respectively. MS parameters were $10 \mathrm{~L} / \mathrm{h}$ for the flow of desolvation gas (nitrogen), $3500 \mathrm{~V}$ for the capillary voltage, $45 \mathrm{psi}$ for the nebulising gas (nitrogen), and $350{ }^{\circ} \mathrm{C}$ for the drying gas temperature.

Calibration Standards. A GAL stock solution of $1.0 \mathrm{mg} / \mathrm{mL}$ was prepared in methanol, and the stock solution was diluted with methanol to obtain GAL working solutions with concentrations of 50-50,000 ng/mL. All prepared solutions were kept at $4{ }^{\circ} \mathrm{C}$ until further use.

To obtain calibration standards, $10 \mu \mathrm{L}$ of appropriate working solution was placed in $1.5 \mathrm{~mL}$ tubes and evaporated to dryness. Subsequently, $100 \mu \mathrm{L}$ of blank rat plasma or mouse tissue homogenate was added to dissolve the dried residue to give final GAL concentrations of 5, 10, 50,100, 200, 500, 1000, and $5000 \mathrm{ng} / \mathrm{mL}$. Quality-control (QC) samples were independently prepared at concentrations of 8,800 , and $4000 \mathrm{ng} / \mathrm{mL}$ in plasma or tissue homogenate as described for the calibration standards.
Sample Preparation. GAL was extracted from plasma by mixing $100 \mu \mathrm{L}$ of rat plasma or mouse tissue homogenate with $300 \mu \mathrm{L}$ of acetonitrile containing $200 \mathrm{ng} / \mathrm{mL}$ IS and vortexing for $0.5 \mathrm{~min}$. After a 10 -min centrifugation step at $13,000 \mathrm{~g}$ at $4{ }^{\circ} \mathrm{C}, 4 \mu \mathrm{L}$ of supernatant was injected into the UHPLC-MS/MS system for quantification.

Method Validation. Specificity was investigated by analyzing six different batches of blank rat plasma and mouse tissue homogenates. Chromatograms of blank matrices, corresponding matrices spiked with GAL and IS, and actual experimental samples following dosing of GAL were compared. Calibration curves for GAL were determined in triplicate using at least eight appropriate concentrations and were generated by plotting the peak area ratio (GAL/IS) $(Y)$ against the theoretical concentration $(x)$ using a $1 / x^{2}$ weighting.

Intra-day accuracy and precision were assessed in a single day by analyzing six replicate QC samples. Inter-day accuracy and precision were assessed on 3 consecutive days by a similar method. Relative error (RE, \%) and relative standard deviation (RSD, \%) were used to express accuracy and precision, respectively. Intra- and inter-run accuracy and precision for QC concentrations of both within $15 \%$ were acceptable.

The matrix effect of GAL was determined by comparing the peak areas obtained from post-extraction rat plasma or mouse liver spiked with GAL versus unextracted standards in the mobile phase at three different QC concentrations. Using this approach, the matrix effect of IS was evaluated at $50 \mathrm{ng} / \mathrm{mL}$.

The recovery of GAL in matrices, namely, rat plasma and mouse liver, was calculated by comparing peak areas obtained from GAL added to and extracted from the biological matrix with those obtained using pure authentic standards at three corresponding concentrations.

The stability of GAL was assessed by analyzing triplicate corresponding matrix samples at different $\mathrm{QC}$ concentrations under various storage conditions. The short-term stability was determined by analyzing spiked samples after exposure at room temperature for $12 \mathrm{~h}$, and ready-to-inject samples were placed in the UHPLC autosampler for $24 \mathrm{~h}$. The long-term stability was assessed by analyzing spiked samples after storage at $-80{ }^{\circ} \mathrm{C}$ for 30 days. The freeze-thaw stability was assessed after three freeze-thaw cycles $\left(-80\right.$ to $\left.25^{\circ} \mathrm{C}\right)$.

Pharmacokinetics. Eighteen SD rats were assigned to three groups $(n=6)$. Six rats received $2 \mathrm{mg} / \mathrm{kg} \mathrm{GAL}$ by intravenous (i.v.) injection, six rats received $9 \mathrm{mg} / \mathrm{kg}$ GAL by i.v. injection, and six rats received $5 \mathrm{mg} / \mathrm{kg}$ by p.o. administration. Blood samples $(\sim 300 \mu \mathrm{L})$ from the tail vein were collected into heparinized tubes at $0.0333,0.25,0.5,1,2,4,6$, and $8 \mathrm{~h}$ and centrifuged at $4000 \mathrm{~g}$ for $10 \mathrm{~min}$. Plasma was then transferred to a new $1.5 \mathrm{~mL}$ tube and kept at $-80{ }^{\circ} \mathrm{C}$ until analysis. Drug and Statistics (DAS) software (version 2.0) was used to calculate pharmacokinetic parameters.
(A)

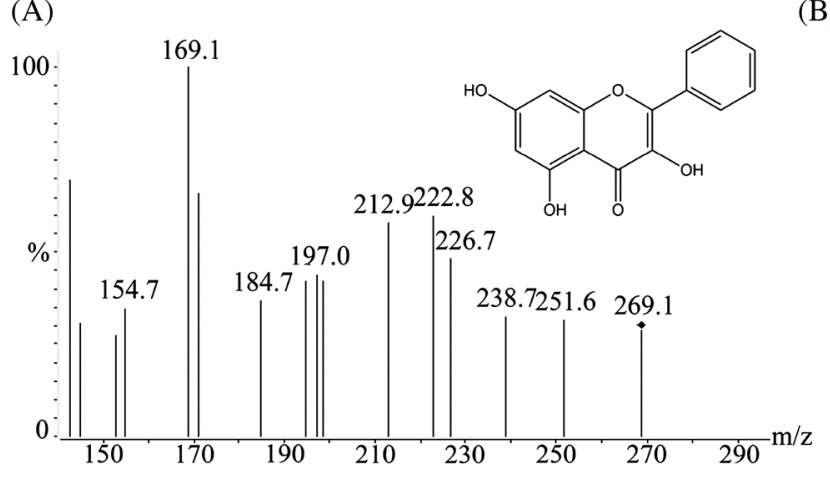

(B)

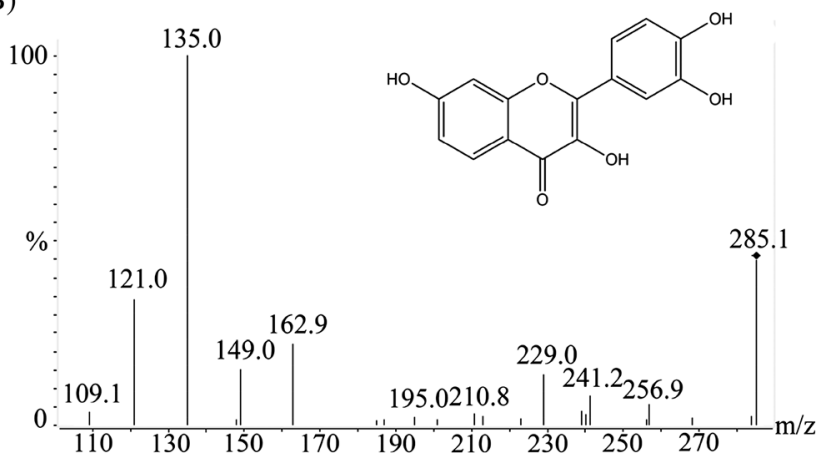

Figure 1. Chemical structures and product ion spectrum of GAL (A) and fisetin (IS, B) 
Tissue Distribution. Twenty-five mice received $18 \mathrm{mg} / \mathrm{kg}$ GAL by intraperitoneal (i.p.) injection. Prior to all collection procedures, each animal was deeply anesthetized by $4 \%$ chloral hydrate. Tissue samples (liver, heart, lung, spleen, brain, and kidney) were collected, washed in saline, and blotted dry with filter paper at $0.25,0.5,2,4$, and $6 \mathrm{~h}$ by sacrificing five mice at each time point. The concentration of GAL in tissues was determined using the developed method.

Artificial Intelligence Model. Back-propagation artificial neural network (BP-ANN) is a type of artificial intelligence that can be used for non-linear mapping, self-organization, and selflearning [19]. It comprises an input layer, a hidden layer, and an output layer. Data in the input layer are processed in the hidden layer by preset functions and delivered to the output layer. In this study, the concentration of GAL in blood, liver, heart, lung, spleen, brain, or kidney tissue could be selected as the input layer. For example, once concentration of GAL in liver, heart, lung, spleen, brain, and kidney was selected as the input layer, its concentration in blood became the output layer. The number of nodes in the hidden layer was calculated using the formula $m=\sqrt{n+l}+a$ as previously described [20, 21]. The BP-ANN model was conducted using Matlab R2011a.
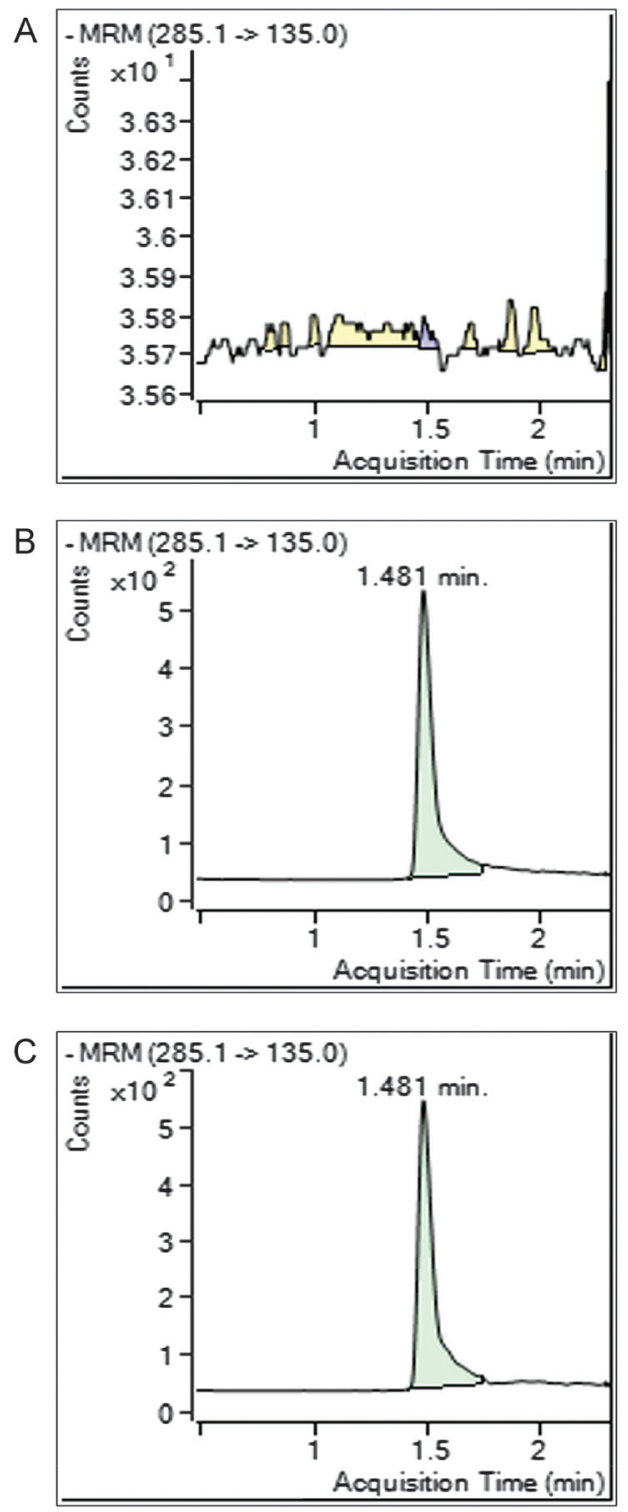

Specificity. GAL and IS were effectively separated by the selected gradient elution procedure, and no interfering endogenous plasma components were observed at the GAL retention time. Representative MS/MS chromatograms of blank rat plasma, blank rat plasma spiked with GAL and IS, and rat plasma samples at $0.25 \mathrm{~h}$ after i.v. administration of $9 \mathrm{mg} / \mathrm{kg}$ GAL are shown in Figure 2. The retention times of GAL and IS were $1.38 \mathrm{~min}$ and $1.77 \mathrm{~min}$, respectively.

Calibration Curves. Calibration curves of GAL in plasma and tissues demonstrated good linearity in the range of 5$5000 \mathrm{ng} / \mathrm{mL}$, with $r^{2}$ greater than 0.990 . Typical regression equations for GAL in rat plasma and mouse tissues were as follows: $Y=0.365127 * x-0.146741$ in plasma $\left(r^{2}=0.9955\right)$, $Y=0.592611^{*} x+0.162256$ in liver $\left(r^{2}=0.9987\right), Y=$ $0.258319 * x-0.072582$ in kidney $\left(r^{2}=0.9966\right), Y=$ $0.561829 * x+0.098174$ in spleen $\left(r^{2}=0.9985\right), Y=$ $0.325866 * x+0.215108$ in lung $\left(r^{2}=0.9981\right), \quad Y=$ $0.719235 * x+0.215108$ in heart $\left(r^{2}=0.9982\right)$, and $Y=$ $0.632574 * x+0.095217$ in brain $\left(r^{2}=0.9962\right)$.

The developed method achieved an LLOQ of $5 \mathrm{ng} / \mathrm{mL}$, which was sufficient for pharmacokinetic analysis following 2
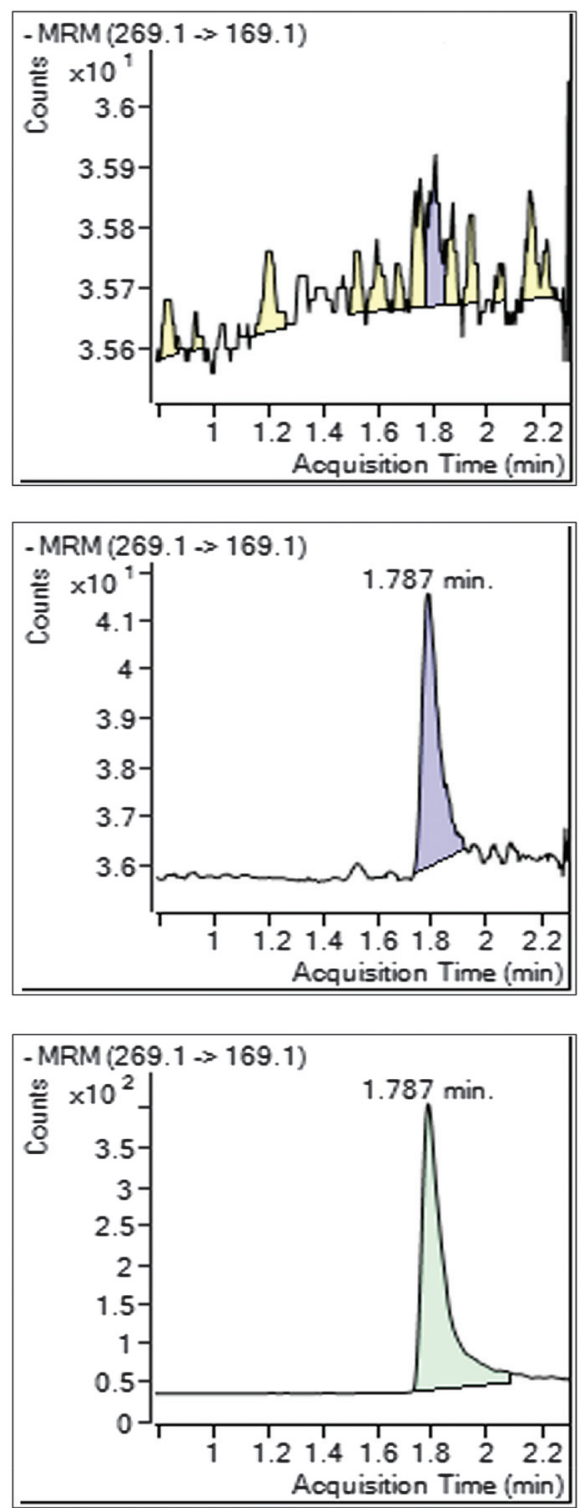

Figure 2. The MS/MS chromatograms of GAL (m/z $269.1 \rightarrow 169.1)$ and fisetin (IS, m/z 285.1 $\rightarrow$ 135.0). (A) Blank rat plasma sample; (B) blank rat plasma sample spiked with GAL and IS; (C) a rat plasma samples after an intravenous administration of GAL at $9 \mathrm{mg} / \mathrm{kg}$ 
and $9 \mathrm{mg} / \mathrm{kg}$ (i.v.) and $5 \mathrm{mg} / \mathrm{kg}$ (p.o.) administration in rats and for tissue distribution evaluation after $18 \mathrm{mg} / \mathrm{kg}$ (i.p.) administration of GAL in mice.

Precision, Accuracy, Extraction Recovery, and Matrix Effects. Table 1 shows the intra- and inter-day precision of GAL in rat plasma and mouse liver at three QC levels. All intra- and inter-day precision RSDs were within $12.1 \%$, and the accuracy ranged from $-4.8 \%$ to $8.1 \%$ and $-2.8 \%$ to $6.3 \%$ for intra- and inter-day precision, respectively. IS recovery was $81.6-92.0 \%$, and all variation in matrix effects was in the range of $94.1-102.1 \%$.

Stability. As shown in Table 2, the results of room temperature, autosampler, long-term (30 days), and freeze-thaw stability analysis demonstrated that GAL was stable under all storage conditions tested.

Pharmacokinetics. Curves of mean rat plasma concentration versus time were determined (Figure 3), and the main pharmacokinetic parameters resulting from the non-compartment model are listed in Table 3.

Tissue Distribution. The distribution of GAL in liver, kidney, spleen, lung, brain, and heart tissue (Figure 4) indicated that GAL was widely distributed in all mouse tissues studied.

BP-ANN Model. Based on the concentration of GAL in blood, liver, heart, lung, spleen, brain, and kidney determined as described above, seven different BP-ANN distribution models were developed. Measured and predicted GAL concentration profiles are shown in Figure 5, and model performance parameters are listed in Table 4. The results showed that BP-ANN models of blood, liver, heart, lung,
Table 3. The pharmacokinetic parameters of GAL in rats following intravenous and oral administration at three different dosages (i.v. $2,9 \mathrm{mg} / \mathrm{kg}$ and p.o. $5 \mathrm{mg} / \mathrm{kg}$ in rats)

\begin{tabular}{|c|c|c|c|c|}
\hline \multirow[t]{2}{*}{ Parameters } & \multirow[t]{2}{*}{ Unit } & p.o. 5 in rats & i.v. 2 in rats & i.v. 9 in rats \\
\hline & & Mean \pm SD & Mean $\pm \mathrm{SD}$ & Mean $\pm \mathrm{SD}$ \\
\hline $\operatorname{AUC}_{(0-t)}$ & $\mathrm{ng} / \mathrm{mL}^{*} \mathrm{~h}$ & $53.9 \pm 15.0$ & $284.7 \pm 98.6$ & $979.2 \pm 213.9$ \\
\hline $\operatorname{AUC}_{(0-\infty)}$ & $\mathrm{ng} / \mathrm{mL} * \mathrm{~h}$ & $54.8 \pm 14.7$ & $285.3 \pm 99.2$ & $989.9 \pm 220.8$ \\
\hline $\operatorname{MRT}_{(0-t)}$ & $\mathrm{h}$ & $0.8 \pm 0.1$ & $0.6 \pm 0.3$ & $0.8 \pm 0.3$ \\
\hline $\operatorname{MRT}_{(0-\infty)}$ & $\mathrm{h}$ & $0.9 \pm 0.1$ & $0.6 \pm 0.3$ & $0.9 \pm 0.3$ \\
\hline$t_{1 / 2 \mathrm{z}}$ & $\mathrm{h}$ & $0.7 \pm 0.2$ & $0.5 \pm 0.2$ & $1.1 \pm 0.4$ \\
\hline CLz & $\mathrm{L} / \mathrm{h} / \mathrm{kg}$ & $97.0 \pm 28.9$ & $7.7 \pm 2.6$ & $9.5 \pm 2.1$ \\
\hline $\mathrm{Vz}$ & $\mathrm{L} / \mathrm{kg}$ & $101.9 \pm 57.8$ & $5.4 \pm 1.1$ & $14.4 \pm 4.3$ \\
\hline$C_{\max }$ & $\mathrm{ng} / \mathrm{mL}$ & $77.6 \pm 26.9$ & $614.3 \pm 166.7$ & $1686.5 \pm 450.6$ \\
\hline$F(\%)$ & - & $7.6 \pm 2.1$ & - & - \\
\hline
\end{tabular}

spleen, brain, and kidney all quickly reached the training goal and achieved a high correlation $(R=1)$.

\section{Discussion}

The GAL structure includes three phenolic hydroxyl groups that make it weakly acidic and hence more suitable for ESI negative detection. In addition, optimization of the mass spectrometry process revealed that the sensitivity was higher with a negative ESI interface, consistent with the previous use of ESI negative detection [15]. MS parameters were selected by directly injecting standards into the mass spectrometer and slowly adjusting the capillary and collision voltages. The most prevalent fragment was detected at $\mathrm{m} / \mathrm{z} 169.1$ with a capillary voltage of $3500 \mathrm{~V}$ and an $F$ of $152 \mathrm{~V}$. Similar selected parameters were

Table 1. Precision, accuracy, extraction recovery, and matrix effect of GAL in rat plasma and mouse liver $(n=6)$

\begin{tabular}{|c|c|c|c|c|c|c|c|}
\hline \multirow[t]{2}{*}{ Sample } & \multirow{2}{*}{$\begin{array}{l}\text { Concentration } \\
(\mathrm{ng} / \mathrm{mL})\end{array}$} & \multicolumn{2}{|c|}{ Precision RSD (\%) } & \multicolumn{2}{|c|}{ Accuracy $(\%)$} & \multirow{2}{*}{$\begin{array}{c}\text { Matrix effect } \\
(\%)\end{array}$} & \multirow{2}{*}{$\begin{array}{c}\text { Recovery } \\
(\%)\end{array}$} \\
\hline & & Inter-day & Intra-day & Inter-day & Intra-day & & \\
\hline \multirow[t]{3}{*}{ Plasma } & 8 & 12.1 & 10.8 & 97.2 & 108.1 & 94.1 & 84.1 \\
\hline & 800 & 2.6 & 5.6 & 106.3 & 103.5 & 95.7 & 86.6 \\
\hline & 4000 & 5.8 & 5.4 & 101.1 & 95.2 & 102.1 & 92.0 \\
\hline \multirow[t]{3}{*}{ Liver } & 8 & 10.5 & 9.7 & 100.6 & 106.5 & 98.2 & 86.9 \\
\hline & 800 & 6.3 & 6.5 & 98.6 & 95.6 & 97.6 & 90.5 \\
\hline & 4000 & 5.5 & 8.9 & 105.8 & 98.2 & 95.9 & 81.6 \\
\hline
\end{tabular}

Table 2. Stabilities of GAL in rat plasma and moue liver under various storage conditions $(n=3)$

\begin{tabular}{|c|c|c|c|c|c|c|c|c|c|}
\hline \multirow[t]{2}{*}{ Sample } & \multirow{2}{*}{$\begin{array}{l}\text { Concentration } \\
\quad(\mathrm{ng} / \mathrm{mL})\end{array}$} & \multicolumn{2}{|c|}{ Ambient, $2 \mathrm{~h}$} & \multicolumn{2}{|c|}{$-20^{\circ} \mathrm{C}, 20$ days } & \multicolumn{2}{|c|}{3 Freeze-thaw } & \multicolumn{2}{|c|}{ Autosampler ambient } \\
\hline & & Precision $(\%)$ & Accuracy $(\%)$ & Precision $(\%)$ & Accuracy $(\%)$ & Precision $(\%)$ & Accuracy $(\%)$ & Precision $(\%)$ & Accuracy $(\%)$ \\
\hline \multirow[t]{3}{*}{ Plasma } & 8 & 5.3 & 96.8 & 8.6 & 102.3 & 8.9 & 109.3 & 1.5 & 100.5 \\
\hline & 800 & 2.8 & 100.6 & 9.7 & 95.6 & 7.6 & 105.5 & 2.5 & 98.9 \\
\hline & 4000 & 4.2 & 98.1 & 10.1 & 98.6 & 10.5 & 102.1 & 1.3 & 103.1 \\
\hline \multirow[t]{3}{*}{ Liver } & 8 & 3.5 & 95.5 & 11.8 & 96.2 & 9.9 & 98.3 & 2.8 & 102.5 \\
\hline & 800 & 4.6 & 98.6 & 7.6 & 95.3 & 7.4 & 103.5 & 1.2 & 99.1 \\
\hline & 4000 & 3.2 & 104.9 & 10.6 & 108.3 & 7.6 & 99.1 & 1.6 & 101.5 \\
\hline
\end{tabular}
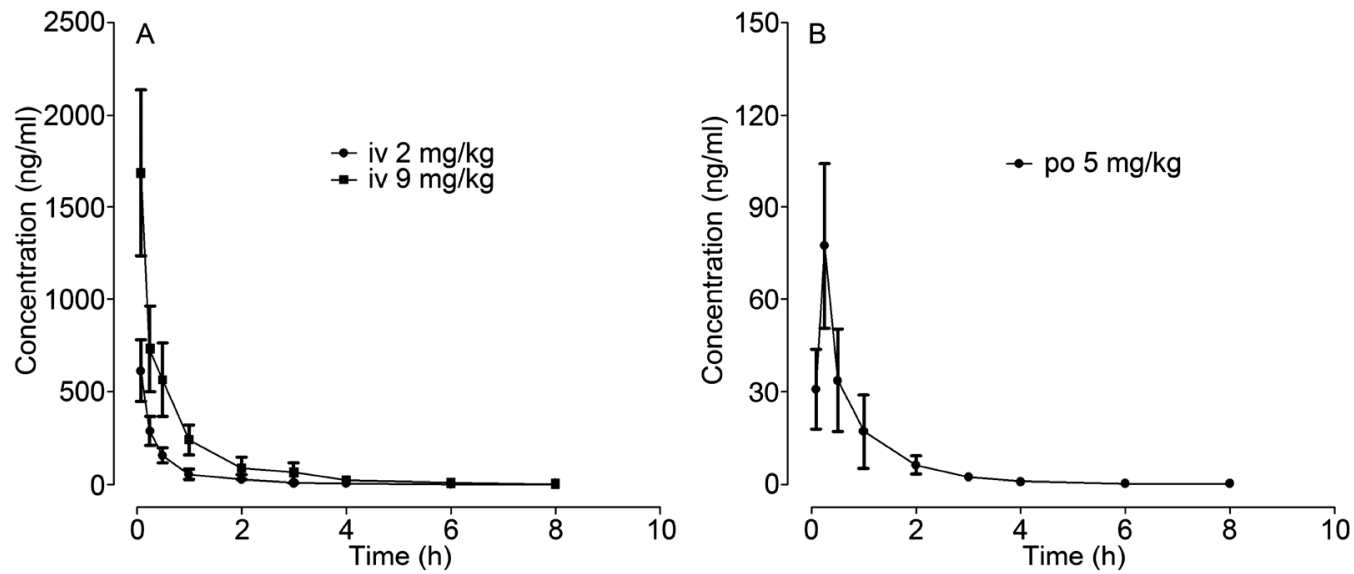

Figure 3. Mean plasma concentration-time curves in rat plasma after intravenous (A) and oral (B) administration of GAL at dose of i.v. 2, 9 mg/kg and p.o. $5 \mathrm{mg} / \mathrm{kg}(n=6)$ 


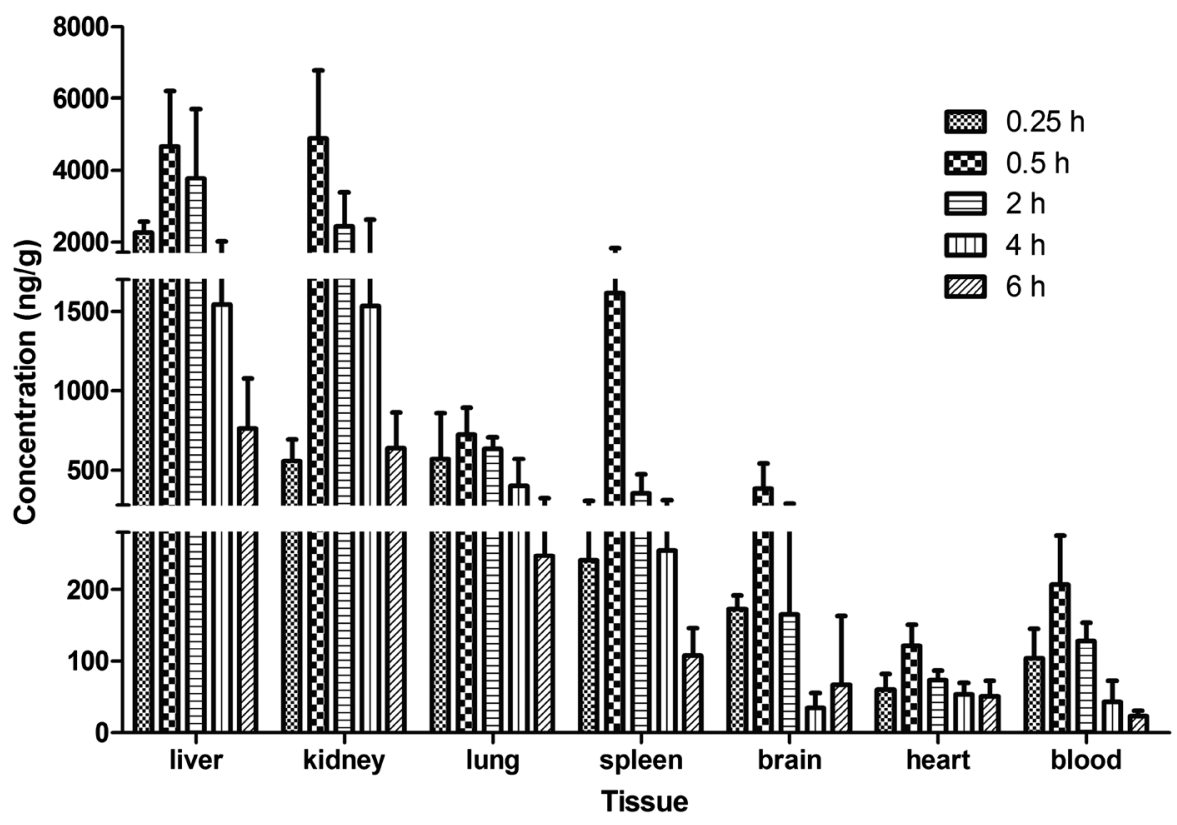

Figure 4. Tissue distribution profile of GAL in various tissues after intraperitoneal administration at a dose of $18 \mathrm{mg} / \mathrm{kg}$ in mice
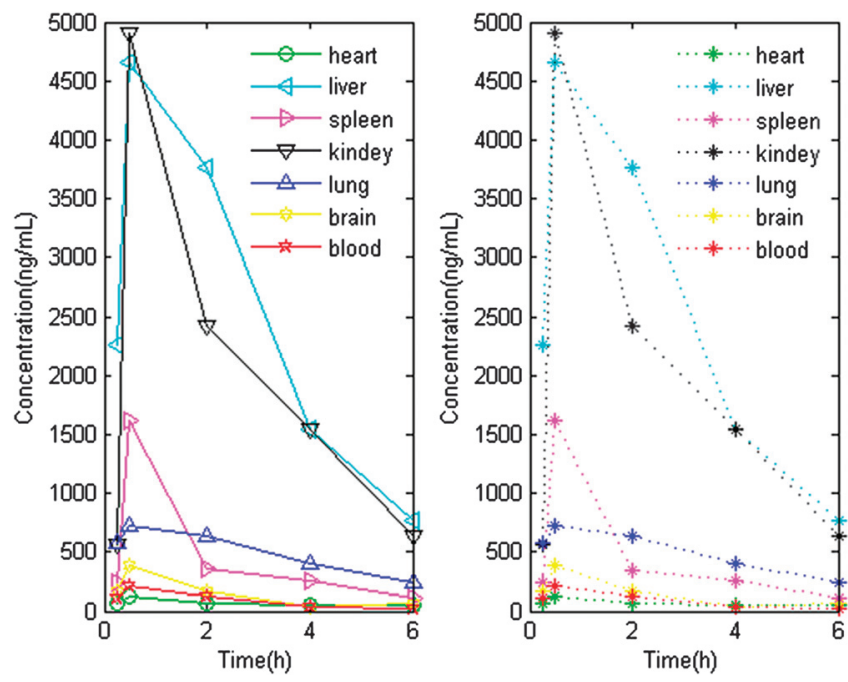

Figure 5. The distributions profiles of GAL in mice after intraperitoneal administration of $18 \mathrm{mg} / \mathrm{kg}$, mean concentration-time curves in heart, liver, spleen, lung, kidney, brain, and blood; measured (solid line) and predicted (dash line) tissues concentrations profiles of GAL generated by BP-ANN model in Matlab

obtained for both GAL and IS, and $\mathrm{m} / \mathrm{z} 269.1 \rightarrow 169.1$ for GAL and $285.1 \rightarrow 135.0$ for IS were selected for MRM mode (Figure 1).

The mobile phase was also selected for UHPLC-MS/MS analysis. Methanol, acetonitrile, water, $0.1 \%$ formic acid, and $0.1 \%$ ammonia were tested in various combinations, and acetonitrile/ $0.1 \%$ formic acid was the final choice because it provided the best chromatographic peaks and acceptable sensitivity. Gradient elution mode was selected because it proved thorough for removing impurities from the column and therefore protecting the chromatographic system [22-25].
A rapid, simple, and convenient sample treatment method with acceptable recovery and matrix effects is needed for LC-MS/MS analysis [26-30]. We mixed plasma samples $(100 \mu \mathrm{L})$ with 200 and $300 \mu \mathrm{L}$ of acetonitrile, and the results showed that the recovery was acceptable ( $\sim 84 \%$ and $95 \%$ ) with both quantities, but matrix effects were not acceptable with $200 \mu \mathrm{L}$ of acetonitrile $(\sim 105 \%$ and $115 \%)$ and were acceptable for $300 \mu \mathrm{L}$ of acetonitrile $(\sim 94 \%$ and $103 \%)$. Therefore, $300 \mu \mathrm{L}$ of acetonitrile was used for protein precipitation in plasma $(100 \mu \mathrm{L})$.

We further investigated the performance of fisetin, and both GAL and fisetin exhibited similar chromatographic retention times. Both were therefore suitable for analysis using the negative ESI interface, and fisetin was used as IS in subsequent experiments.

The pharmacokinetic parameters indicated rapid GAL absorption, extensive distribution, and quick elimination and clearance. After p.o. administration of $5 \mathrm{mg} / \mathrm{kg} \mathrm{GAL}$, the time to reach peak concentration $\left(t_{\max }\right)$ was $15 \mathrm{~min}$, indicating fast absorption of GAL into the blood circulatory system. Clearance, $\mathrm{MRT}_{(0-t)}$, and $t_{1 / 2}$ values were estimated at $97.0 \pm 28.9 \mathrm{~L} / \mathrm{h} / \mathrm{kg}, 0.8 \pm 0.1 \mathrm{~h}$, and $0.7 \pm 0.2 \mathrm{~h}$, respectively, indicating rapid elimination from the circulatory system in rats. The absolute bioavailability of GAL was $7.6 \% \pm 2.1 \%$, which was calculated using the formula

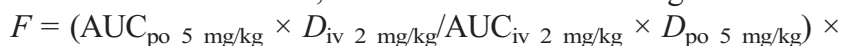
$100 \%$. This compares with a GAL oral bioavailability of $\sim 3.67 \%$ reported previously in the literature [15].

At $0.5 \mathrm{~h}$ after i.p. administration, the concentration of GAL in different tissues was ordered $C_{\text {kidney }}>C_{\text {liver }}>C_{\text {spleen }}>C_{\text {lung }}>$ $C_{\text {brain }}>C_{\text {heart }}(C=$ concentration $)$. At other time points $(0.25,2$, 4 , and $6 \mathrm{~h}$ ), the order was $C_{\text {liver }}>C_{\text {kidney }}>C_{\text {lung }}>C_{\text {spleen }}>$ $C_{\text {brain }}>C_{\text {heart }}$. The relatively high abundance in kidney, liver, and spleen may be correlated with the dense blood vessel network and rich blood supply to these tissues. These results showed that GAL was also present in brain tissue, suggesting that it passes the blood-brain barrier and may therefore have beneficial effects in the treatment of ischemic stroke.

Table 4. The fitness index of BP-ANN model performed in blood, liver, heart, lung, spleen, brain, and kidney

\begin{tabular}{|c|c|c|c|c|c|c|c|}
\hline Index & Heart & Liver & Spleen & Kidney & Lung & brain & blood \\
\hline Mean squared error & $1.35 \times 10^{-10}$ & $4.58 \times 10^{-9}$ & $6.96 \times 10^{-6}$ & $2.88 \times 10^{-6}$ & $4.72 \times 10^{-8}$ & $4.08 \times 10^{-7}$ & $3.02 \times 10^{-10}$ \\
\hline The magnitude of the gradient & $4.85 \times 10^{-5}$ & $1.81 \times 10^{-4}$ & $6.17 \times 10^{-3}$ & $6.42 \times 10^{-3}$ & $9.05 \times 10^{-4}$ & $1.28 \times 10^{-3}$ & $7.70 \times 10^{-5}$ \\
\hline Validation checks & 0 & 0 & 0 & 0 & 0 & 0 & 0 \\
\hline
\end{tabular}


BP-ANN is a powerful artificial modelling method that is widely used in medicine that differs from support vector machines, which are specialized for classification and identification [31]. BP-ANN has been used to predict the plasma concentration, pharmacokinetics, and pharmaceutical properties associated with dosage, as well as predicting prognosis of chronic diseases [32-34]. In general, the more relevant the selection of variables in the input layer, the higher the accuracy of the model and the more reliable the predictions. In this study, BP-ANN models of blood, heart, liver, spleen, lung, brain, and kidney tissue all showed excellent performance parameters, indicating that their concentrations were correlated. The blood BP-ANN model had the lowest mean squared error, and that of the heart model was similar. On the other hand, BP-ANN models of spleen and kidney had a higher mean squared error, suggesting that blood and heart were more closely associated with each other than spleen and kidney.

\section{Conclusion}

A fast, simple, and reliable UHPLC-MS/MS method for the quantification of GAL was developed, validated, and successfully applied to study pharmacokinetics and tissue distribution. Compared with previously described determination methods [13-17], our new approach has several advantages including simple and fast sample treatment, short run time, and selective MRM mode, making it a better choice for highthroughput assays of GAL in biological samples. The pharmacokinetic parameters following i.v. and p.o. administration showed that GAL displayed rapid absorption and elimination. Tissue distribution data showed that GAL was abundant in liver, kidney, spleen, and lung, while smaller amounts were present in brain tissue. This is the first study to identify the target tissues of GAL, and the results may help to elucidate the mechanisms underlying its therapeutic effects in vivo. The developed BP-ANN model achieved high accuracy and could prove useful for comprehension of metabolic characteristics in future studies.

\section{Disclosure statement}

The authors report no conflicts of interest.

\section{References}

1. Wu, C.; Chen, J.; Chen, C.; Wang, W.; Wen, L.; Gao, K.; Chen, X.; Xiong, S.; Zhao, H.; Li, S. Sci. Rep. 2015, 5, 16151.
2. So, F. V.; Guthrie, N.; Chambers, A. F.; Moussa, M.; Carroll, K. K. Nutr. Cancer. 1996, 26, 167-181.

3. Benguedouar, L.; Lahouel, M.; Gangloff, S. C.; Durlach, A.; Grange, F.; Bernard, P.; Antonicelli, F. Anticancer Agents Med. Chem. 2016.

4. Cao, J.; Wang, H.; Chen, F.; Fang, J.; Xu, A.; Xi, W.; Zhang, S.; Wu, G., and Wang, Z. Mol. Med. Rep. 2016, 13, 4238-4244.

5. Bacanli, M.; Basaran, A. A.; Basaran, N. Drug Chem. Toxicol. 2016, 1-7.

6. Sivakumar, A. S.; Anuradha, C. V. Chem. Biol. Interact. 2011, 193 141-148.

7. Kim, H. H.; Bae, Y.; Kim, S. H. Food Chem. Toxicol. 2013, 57, 209-216.

8. Zha, W. J.; Qian, Y.; Shen, Y.; Du, Q.; Chen, F. F.; Wu, Z .Z.; Li, X.;

Huang, M. Evid Based Complement Alternat. Med. 2013, 2013, 767689.

9. Afolayan, A. J.; Meyer, J. J. J. Ethnopharmacol. 1997, 57, 177-181.

10. Cushnie, T. P.; Lamb, A. J. J. Ethnopharmacol. 2005, 101, 243-248.

11. Cushnie, T. P.; Lamb, A. J. Phytomedicine 2006, 13, 187-191.

12. Morello, S.; Vellecco, V.; Alfieri, A.; Mascolo, N.; Cicala, C. Life Sci.

2006, $78,825-830$.

13. Feng, W. H.; Zhang, H. H.; Zhang, Y.; Sun, M.; Niu, J. L. J. Chromatogr. B Analyt. Technol. Biomed. Life Sci. 2015, 998-999, 26-30.

14. Careri, M.; Elviri, L.; Mangia, A. Rapid Commun. Mass Spectrom. 1999, 13, 2399-2405.

15. Chen, F.; Tan, Y. F.; Li, H. L.; Qin, Z. M.; Cai, H. D.; Lai, W. Y.; Zhang, X. P.; Li, Y. H.; Guan, W. W.; Li, Y. B.; Zhang, J. Q. Chem. Cent. J. 2015, 9,14

16. Ristivojevic, P.; Trifkovic, J.; Gasic, U.; Andric, F.; Nedic, N.; Tesic, Z.;

Milojkovic-Opsenica, D. Phytochem. Anal. 2015, 26, 127-136.

17. Gardana, C.; Simonetti, P.; Berti, C.; Pietta, P. Rapid Commun. Mass Spectrom. 2007, 21, 3849-3854.

18. Ye, W.; Chen, R.; Sun, W.; Huang, C.; Lin, X.; Dong, Y.; Wen, C.; Wang,

X. J. Chromatogr. B Analyt. Technol. Biomed. Life Sci. 2017, 1060, 144-149.

19. Luis, A.; Martins, J. D.; Silva, A.; Ferreira, I.; Cruz, M. T.; Neves, B. M. Free Radic. Biol. Med. 2014, 77, 217-229.

20. Wen, C.; Zhang, M.; Zhang, Y.; Sun, F.; Ma, J.; Hu, L.; Lin, G.; Wang, X. Biomed. Chromatogr. 2016, 30, 81-84.

21. Lin, B.; Lin, G.; Liu, X.; Ma, J.; Wang, X.; Lin, F.; Hu, L. Int. J. Clin. Exp. Med. 2015, 8, 22352-22358.

22. Wang, S.; Wu, H.; Geng, P.; Lin, Y.; Liu, Z.; Zhang, L.; Ma, J.; Zhou, Y.;

Wang, X.; Wen, C. Biomed. Chromatogr. 2016, 30, 1145-1149.

23. Wen, C.; Wang, S.; Huang, X.; Liu, Z.; Lin, Y.; Yang, S.; Ma, J.; Zhou, Y.;

Wang, X. Biomed. Chromatogr. 2015, 29, 1805-1810.

24. Ma, J.; Wang, S.; Zhang, M.; Zhang, Q.; Zhou, Y.; Lin, C.; Lin, G.;

Wang, X. Biomed. Chromatogr. 2015, 29, 1203-1212.

25. Wang, X.; Chen, M.; Wen, C.; Zhang, Q.; Ma, J. Biomed. Chromatogr. 2013, 27, 1801-1806.

26. Ma, J.; Wang, S.; Huang, X.; Geng, P.; Wen, C.; Zhou, Y.; Yu, L.; Wang, X. J. Pharm. Biomed. Anal. 2015, 111, 131-137.

27. Zhang, Q.; Wen, C.; Xiang, Z.; Ma, J.; Wang, X. J. Pharm. Biomed. Anal. 2014, 90, 134-138.

28. Wang, S.; Wu, H.; Huang, X.; Geng, P.; Wen, C.; Ma, J.; Zhou, Y.; Wang,

X. J. Chromatogr. B Analyt. Technol. Biomed. Life Sci. 2015, 990, 118-124.

29. Zhao, J.; Shin, Y.; Chun, K. H.; Yoon, H. R.; Lee, J. J. Chromatogr. Sci. 2016, 54, 561-568.

30. Zhang, S.; Yang, F.; Guo, B.; Chen, Y.; Wu, X.; Liang, W.; Shi, Y.; Zhang, J. J. Chromatogr. Sci. 2016, 54, 230-236.

31. Wang, X.; Zhang, M.; Ma, J.; Zhang, Y.; Hong, G.; Sun, F.; Lin, G.; Hu, L. Biol. Pharm. Bull 2015, 38, 470-475.

32. Yamamura, S.; Kawada, K.; Takehira, R.; Nishizawa, K.; Katayama, S.; Hirano, M.; Momose, Y. Biomed. Pharmacother. 2004, 58, 239-244.

33. Chen, H.; Yang, B.; Liu, D.; Liu, W.; Liu, Y.; Zhang, X.; Hu, L. PLoS One 2015, 10, e0143003.

34. Hu, L.; Hong, G.; Ma, J.; Wang, X.; Lin, G.; Zhang, X.; Lu, Z. Biomed. Res. Int. 2015, 2015, 298253. 